\title{
Veno-venous extracorporeal membrane oxygenation with interatrial shunting: A novel approach to lung transplantation for patients in right ventricular failure
}

\author{
Daniele Camboni, MD, Begum Akay, MD, Joshua R. Pohlmann, MS, Kelly L. Koch, MS, \\ Jonathan W. Haft, MD, Robert H. Bartlett, MD, and Keith E. Cook, PhD
}

\begin{abstract}
Objective: This study evaluated the effectiveness of an atrial septostomy with veno-venous extracorporeal membrane oxygenation in alleviating high afterload right ventricular dysfunction while providing respiratory support. This technique could be applied as a bridge to lung transplantation.
\end{abstract}

\begin{abstract}
Methods: Sheep $(56 \pm 3 \mathrm{~kg}$ ) underwent a clamshell thoracotomy and hemodynamic instrumentation, including right ventricular pressure and cardiac output. Sheep with and without tricuspid insufficiency $(n=5$ each) were examined. While sheep were on extracorporeal membrane oxygenation, right ventricular failure was established by banding the pulmonary artery until cardiac output was $40 \%$ to $60 \%$ of baseline. An extracardiac atrial shunt was created with modified vascular grafts to examine the effect of shunt flow on hemodynamics. Hemodynamic data were thus collected at baseline, during right ventricular failure, and for 1 hour at $100 \%$ (fully open), $70 \%$, $50 \%$, and $30 \%$ of baseline shunt flow.
\end{abstract}

Results: Cardiac output was returned to baseline values (tricuspid insufficiency: $5.2 \pm 0.2 \mathrm{~L} / \mathrm{min}$, without tricuspid insufficiency: $5.3 \pm 1.2 \mathrm{~L} / \mathrm{min}$ ) with $100 \%$ shunt flow (tricuspid insufficiency: $4.8 \pm 1.1 \mathrm{~L} / \mathrm{min}$, without tricuspid insufficiency: $4.8 \pm 1.0 \mathrm{~L} / \mathrm{min} ; P=.15$ ) but remained significantly lower than baseline at $70 \%$ to $30 \%$ shunt flow. At $100 \%$ shunt flow, tricuspid insufficiency shunt flow was $1.4 \pm 0.8 \mathrm{~L} / \mathrm{min}$ and without tricuspid insufficiency shunt flow was $1.7 \pm 0.2 \mathrm{~L} / \mathrm{min}$. Right ventricular pressure was significantly elevated over baseline values at all shunt flows $(P<.001)$. In the group without tricuspid insufficiency, all sheep died beginning at the $70 \%$ shunt condition, whereas all animals with tricuspid insufficiency survived the entire experiment. Normal arterial blood gases were maintained under all conditions.

Conclusions: An atrial septostomy accompanied by veno-venous extracorporeal membrane oxygenation is capable of eliminating right ventricular failure while maintaining normal arterial blood gases if sufficient shunt flows are achieved. The presence of tricuspid insufficiency improves the efficacy of the shunt. (J Thorac Cardiovasc Surg 2011;141:537-42)

\section{Supplemental material is available online.}

Pulmonary arterial hypertension has a prevalence of approximately 15 per million in both the United States and Europe. ${ }^{1,2}$ The prognosis of this disease is poor, with approximately $15 \%$ mortality within 1 year on modern

\footnotetext{
From the Extracorporeal Life Support Laboratory, Department of Surgery, University of Michigan Medical School, Ann Arbor, Mich.

This study was partially supported by grant RO1HL069420-0 from the National Heart, Lung, and Blood Institute of the National Institutes of Health. Daniele Camboni was partially supported by the German Research Foundation (DFG CA 861/1-1).

Disclosures: Authors have nothing to disclose with regard to commercial support.

Received for publication April 19, 2010; revisions received July 8, 2010; accepted for publication Aug 1, 2010.

Address for reprints: Daniele Camboni, MD, Extracorporeal Life Support Laboratory, Department of Surgery, University of Michigan, B560-B Medical Science Research Building II, 1150 West Medical Center Drive, Ann Arbor, MI 48109 (E-mail: dcamboni@arcor.de).

$0022-5223 / \$ 36.00$

Copyright (C) 2011 by The American Association for Thoracic Surgery

doi:10.1016/j.jtcvs.2010.08.092
}

therapy ${ }^{2}$ and $60 \%$ 2-year mortality if untreated. ${ }^{3}$ This patient population is routinely listed for lung transplantation when refractory to conventional medical therapy. However, because of a lack of available donor organs, a high number of patients die on the waiting list or become unsuitable candidates for lung transplantation. The impact of organ shortage can be estimated by the high number of approximately 2500 patients who have died on the waiting list in the United States over the last 5 years. ${ }^{4}$ A major contributing factor to morbidity and mortality on the transplantation waiting list is right ventricular (RV) failure. Therefore, RV dysfunction is one of the most important prognostic factors in pulmonary hypertension. ${ }^{5}$ As a result, intensive efforts are made to develop new therapeutic modalities for combined lung and RV support. This has led to several novel drugs and therapies entering clinical practice to facilitate bridging patients to lung transplantation with considerable success. To date, a poorly understood treatment option has been an atrial septostomy. ${ }^{6,7}$ The reported success rates of atrial septostomies for bridging patients to lung transplantation range from $30 \%$ to $40 \%{ }^{6}$ These low success rates can be 


$$
\begin{array}{ll}
\text { Abbreviations and Acronyms } \\
\begin{array}{ll}
\text { CO } & \text { cardiac output } \\
\varnothing \mathrm{TI} & =\text { without tricuspid insufficiency } \\
\mathrm{Q}_{\text {Shunt }} & =\text { shunt flow rate } \\
\mathrm{RAP} & =\text { right atrial pressure } \\
\mathrm{RV} & =\text { right ventricular } \\
\mathrm{RVP} & =\text { right ventricular pressure } \\
\mathrm{TI} & =\text { tricuspid insufficiency } \\
\text { VV ECMO } & =\text { veno-venous extracorporeal } \\
& \text { membrane oxygenation }
\end{array}
\end{array}
$$

explained by an oftentimes unpredictable decrease in arterial oxygen saturation. Therefore, patients with severe gas exchange physiology are not suitable candidates for this approach, which has limited the application of atrial septostomies as a bridge to transplantation. These patients would then require extracorporeal blood oxygenation with venovenous extracorporeal membrane oxygenation (VV ECMO). Reports on the use of ECMO alone as a bridge to lung transplantation are isolated, and the outcomes remain mixed because of the low sample size of patients. However, recent major technical advances in ECMO enable patients to be supported with relative safety for several weeks up to months, facilitating even extubation until donor organs become available. ${ }^{8,9}$ Several large series now report improved survival for patients with acute severe respiratory failure treated with VV ECMO. ${ }^{10,11}$ The results obtained by the CESAR-Trial indicate a possible advantage for ECMO over conventional treatment for reversible severe pulmonary failure. ${ }^{12,13}$ Therefore, the use of VV ECMO for severe, refractory lung failure can be expected to increase in the near future.

To date, there is no published evidence to support the effectiveness of an atrial septostomy and VV ECMO at treating concomitant respiratory and RV failure. This study was designed to evaluate the feasibility of this new approach as a potential novel bridge to lung transplantation and the hemodynamic factors affecting its success. This study uses an extra-anatomic interatrial shunt in a large animal model to assess the effect of the shunt flow rate $\left(\mathrm{Q}_{\text {shunt }}\right)$ and tricuspid insufficiency (TI) on RV function and arterial blood gases.

\section{MATERIALS AND METHODS}

All animals received care compliant with the "Principles of Laboratory Animal Care" formulated by the National Society for Medical Research and the "Guide for the Care and Use of Laboratory Animals" prepared by the National Academy of Sciences and published by the National Institutes of Health. The study was approved by the University of Michigan Committee on Use and Care of Animals.

\section{Surgical Instrumentation}

Adult male sheep $(56 \pm 3 \mathrm{~kg})$ were anesthetized using a standard protocol as previously described and used by our laboratory. ${ }^{14}$ The ventilator
(Narkomed 600; North American Draeger, Telford, Pa) was set initially at a tidal volume of $10 \mathrm{~mL} / \mathrm{kg}$ and a frequency of 12 to 15 breaths $/ \mathrm{min}$. It was adjusted as needed to maintain the arterial $\mathrm{PCO}_{2}$ between 35 and $45 \mathrm{~mm} \mathrm{Hg}$ with a peak inspiratory pressure less than $30 \mathrm{~cm} \mathrm{H}_{2} \mathrm{O}$. Arterial and venous accesses were established by carotid and jugular catheterization using PVC tubing (Abbott Critical Care Systems, North Chicago, Ill). The arterial catheter was connected to a fluid coupled pressure transducer (Abbot Critical Care Systems) to monitor arterial pressure, which was displayed continuously (Marquette Electronics, Milwaukee, Wis).

A clamshell thoracotomy was performed, entering the chest cavity through the fourth intercostal space. A $60 \mathrm{mg}$ dose of intravenous ketorolac (Hospira, Inc, Lake Forest, Ill) was given before the transverse sternotomy. After opening the pericardium, a 16F angiocatheter (Becton, Dickinson Infusion Therapy Systems Inc, Sandy, Utah) was inserted into the right atrium and connected to a fluid-coupled pressure transducer to measure right atrial pressure (RAP). A 6F micromanometer tipped pressure probe (Millar Instruments, Inc, Houston, Tex) was inserted into the conus region of the $\mathrm{RV}$ free wall to measure RV pressure (RVP). An ultrasonic perivascular flow probe (T206 Flowmeter; Transonic Systems, Ithaca, NY) was placed around the ascending aorta to measure continuous cardiac output (CO). Heparin (100 U/kg, intravenously; Baxter Healthcare Corporation, Deerfield, Ill) was administered to maintain activated clotting times greater than 400 seconds.

Right to left interatrial shunting was realized with a custom-made extracardial shunt consisting of 40-cm 31F long tubing (Fisher Scientific Company, Pittsburgh, Pa) and 2 right-angled metal $31 \mathrm{~F}$ cannulas on both ends (Figure E1). The extracardial shunt was introduced through pursestring sutures into the right and left atrial appendages. To measure the flow rate through the interatrial shunt, $Q_{\text {Shunt }}$, an ultrasonic tubing flow probe was attached (Transonic Systems). In one group of sheep $(n=5)$, TI was created by introducing a custom-made fenestrated $16 \mathrm{~F}$ cannula through the right atrium into the right ventricle. After introducing the cannula, it was secured in place. TI was verified by significant pulsatile backflow in the jugular vein (Cannon-V waves). In another group $(n=5)$, TI was not created (ØTI).

\section{Cardiopulmonary Bypass and Extracorporeal Membrane Oxygenation}

The ECMO circuit consisted of a centrifugal pump (Biomedicus $520 \mathrm{D}$; Medtronic Minneapolis, Minn), heater unit (ECMO-Temp, Zimmer, Dover, OH), oxygenator (Capiox SX; Terumo, Ann Arbor, Mich), and 30F Tygon tubing. The circuit was primed with $800 \mathrm{~mL}$ Lactated Ringer solution mixed with $50 \mathrm{~mL}$ of bicarbonate solution. ECMO was established with standard techniques for VV ECMO by drainage from the iliac vein with an $18 \mathrm{~F}$ cannula (TenderFlow; Terumo Cardiovascular, Ann Arbor, Mich) and reinfusion into the superior vena cava with an $18 \mathrm{~F}$ straight cannula introduced through the right jugular vein (L-Series; Terumo Cardiovascular). Before initiating ECMO, $500 \mathrm{mg}$ of methylprednisolone $(0.5 \mathrm{~g}$ intravenously; Pfizer, New York, NY) was administered to reduce the inflammatory response to the foreign surfaces of the circuit. ECMO flow was kept between 2.5 and $3.5 \mathrm{~L} / \mathrm{min}$, and $\mathrm{O}_{2}$ at $100 \% \mathrm{FIO}_{2}$ was delivered at a flow rate of 2 to $6 \mathrm{~L} / \mathrm{min}$ based on arterial blood gases. On initiation of ECMO, the ventilator rate was changed to 8 breaths $/ \mathrm{min}$. Low doses of norepinephrine (Sicor, Irvine, Calif; 0.05-0.1 $\mu \mathrm{g} / \mathrm{min} / \mathrm{kg}$ intravenously) were administered to keep mean arterial pressure greater than $50 \mathrm{~mm} \mathrm{Hg}$ before the establishment of ECMO to reduce the vasodilatory effects of the inflammatory response.

\section{Experimental Procedure and Data Collection}

After initiating ECMO, 10 minutes were allowed for equilibration and a baseline data set was acquired. A complete data set consisted of RAP, $\mathrm{RVP}$, pulmonary artery pressure, $\mathrm{CO}$, and $\mathrm{Q}_{\text {shunt }}$. At each data acquisition point, all parameters were collected manually using Excel (Microsoft, Redmond, Wash). RVP was also acquired digitally at $250 \mathrm{~Hz}$ using Labview 7.0 
(National Instruments, Austin, Tex) and stored on a personal computer (Dell Computer Corporation, Round Rock, Tex).

After collection of baseline data, RV failure was created by progressively banding the pulmonary artery. RV failure was defined as a $40 \%$ to $60 \%$ decrease of CO from baseline and a 2 -fold increase in RAP. After 10 minutes of RV failure, a complete data set was taken. The atrial shunt was then opened. Flow was left fully open $(100 \%)$ for 1 hour followed by 1 hour each at $70 \%, 50 \%$, and $30 \%$. This flow was titrated using a Hoffman clamp on the shunt. At each shunt condition, data were acquired after 1 hour, except arterial, right, and left atrial blood gases, which were collected every 20 to 30 minutes. At the end of the experiment, sheep were euthanized using 90 to $150 \mathrm{mg} / \mathrm{kg}$ of pentobarbital (Fatal-Plus; Vortech Pharmaceuticals, Dearborn, Mich).

\section{Statistical Evaluation}

All data are presented as mean \pm standard deviation collected in each experimental condition. All manually collected data from survivors and nonsurvivors were compared using the mixed-model analysis within SPSS 17 (SPSS Inc, Chicago, Ill). On comparison of the hemodynamic variables, the experiment number was the subject variable and the shunt flow condition and TI group were the independent variables. Multiple comparisons confidence intervals were adjusted according to the Bonferroni method to minimize type I errors. To compare the effect of TI group on hemodynamics or gas exchange, the subject and dependent variables remain the same, but baseline and RV failure data were excluded to focus on the effect of TI during ECMO and interatrial support.

\section{RESULTS \\ Survival}

Right to left atrial shunting successfully eliminated complete RV failure under all shunt conditions when TI was present. On the other hand, animals with a competent tricuspid valve (ØTI) experienced complete RV failure and death. One animal died at the end of the $70 \%$ shunt flow period; another animal died at 50\% shunt flow; 2 animals died during the $30 \%$ shunt flow period; and the remaining last ØTI animal died immediately after completion of the $30 \%$ period of 60 minutes.

\section{Hemodynamics}

Baseline CO was similar in both groups with $5.2 \pm 0.2 \mathrm{~L} /$ $\min$ in the TI group and $5.3 \pm 1.2 \mathrm{~L} / \mathrm{min}$ in the ØTI group (Figure 1). After RV failure was established, $\mathrm{CO}$ decreased to $2.2 \pm 1.1 \mathrm{~L} / \mathrm{min}$ in the TI group and $2.3 \pm 0.4 \mathrm{~L} / \mathrm{min}$ in the ØTI group $\left(P<10^{-10}\right)$. With $100 \%$ shunt flow, $\mathrm{Q}_{\text {Shunt }}=$ $1.4 \pm 0.8 \mathrm{~L} / \mathrm{min}$ in the TI group and $1.7 \pm 0.2 \mathrm{~L} / \mathrm{min}$ in ØTI group (Figure E2), and $\mathrm{CO}$ was not significantly different than baseline in both groups (TI: $4.8 \pm 1.0 \mathrm{~L} / \mathrm{min}$; ØTI: $4.8 \pm 1.1 \mathrm{~L} / \mathrm{min} ; P=.74)$. Thereafter, $\mathrm{CO}$ diminished significantly with decreasing shunt flow. $\mathrm{CO}$ became significantly lower at $70 \%$ compared with baseline in both groups (TI: $4.3 \pm 1.04 \mathrm{~L} / \mathrm{min}$; ØTI: $4.5 \pm 0.8 \mathrm{~L} / \mathrm{min}$; $P<.01)$ and was significantly lower than baseline at $50 \%$ and $30 \%\left(P<10^{-4}\right.$ and $\left.P<.001\right)$. There was no significant difference between TI and ØTI groups $(P=.60)$.

Mean RVP increased significantly from $12.7 \pm 1.2 \mathrm{~mm}$ $\mathrm{Hg}$ at baseline to $24 \pm 2 \mathrm{~mm} \mathrm{Hg}$ at the imposed RV failure

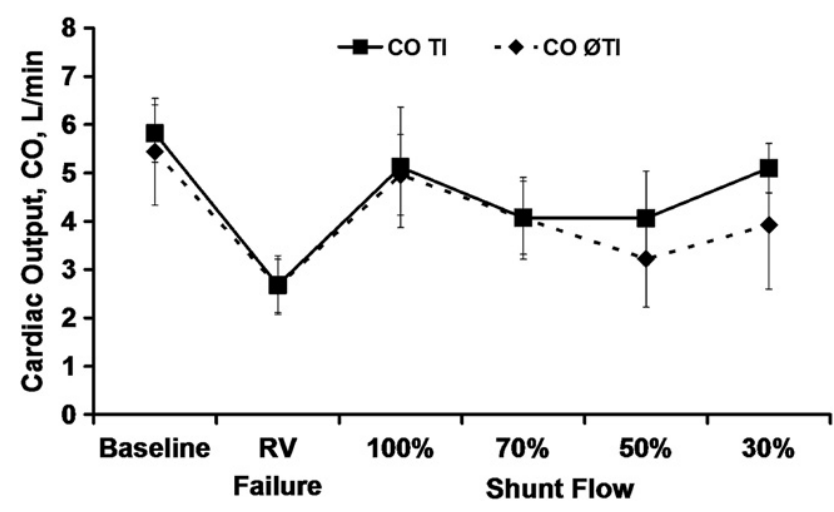

FIGURE 1. $\mathrm{CO}$ at each shunt condition in TI and ØTI groups. $C O$, Cardiac output; $R V$, right ventricular; $T I$, tricuspid insufficiency; $\varnothing T I$, without tricuspid insufficiency.

condition in the TI group and from $11.3 \pm 1.5 \mathrm{~mm} \mathrm{Hg}$ to $24 \pm 7 \mathrm{~mm} \mathrm{Hg}$ in the ØTI group at the same conditions (Figure 2; $P<10^{-7}$ ). Mean RVP at full shunt flow (TI: $25 \pm 7 \mathrm{~mm} \mathrm{Hg}$; ØTI: $23 \pm 10 \mathrm{~mm} \mathrm{Hg}$ ) was significantly higher than at baseline in both groups $(P<.01)$ and remained significantly elevated at all shunt flows $(P<.001-$ .01). Typical examples of RVP tracings are shown in Figure E3. There was no significant difference between TI and $\varnothing$ TI groups $(P=.77)$.

Results for mean pulmonary artery pressure followed similar trends as mean RVP (Table 1), with significantly elevated values at the RV failure condition $(P<.001)$ and all shunt flows $(P<.001-.05)$ with the exception of 50\%, which approaches significance $(P=.08)$. Once again, there was no significant difference between TI and ØTI groups $(P=.48)$. Mean RAP was also significantly elevated at the RV failure condition $\left(P<10^{-7}\right)$ and at all shunt flows $(P<.001-.05)$. However, unlike mean RVP, mean RAP decreased with increasing shunt flow, suggesting improved right to left blood flows. In the TI group, this effect is less pronounced, with

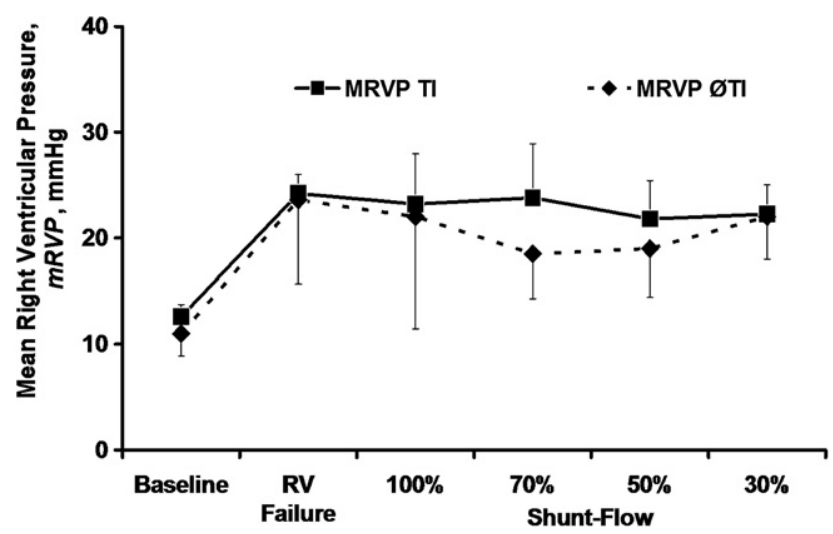

FIGURE 2. Mean RVP at each shunt condition in TI and ØTI groups. $R V$, Right ventricular; $T I$, tricuspid insufficiency; $R V P$, right ventricular pressure. 
TABLE 1. Pulmonary artery, radial artery, and left artery pressures (mm Hg)

\begin{tabular}{|c|c|c|c|c|c|c|}
\hline & \multicolumn{6}{|c|}{ Condition } \\
\hline & BL & Right ventricular failure & $100 \%$ shunt & $70 \%$ shunt & $50 \%$ shunt & $30 \%$ shunt \\
\hline \multicolumn{7}{|c|}{ Mean PAP } \\
\hline $\mathrm{TI}$ & $15.4 \pm 2.3$ & $26.6 \pm 4.3$ & $26.8 \pm 5.1$ & $26.5 \pm 5.2$ & $24.9 \pm 6.4$ & $30.9 \pm 13.3$ \\
\hline ØTI & $12.6 \pm 5.8$ & $25.4 \pm 5.7$ & $25.2 \pm 6.9$ & $23.1 \pm 7.7$ & $21.8 \pm 6.3$ & $24.0 \pm 6.9$ \\
\hline \multicolumn{7}{|c|}{ Mean RAP } \\
\hline TI & $3.6 \pm 2.5$ & $7.6 \pm 2.7$ & $7.1 \pm 2.2$ & $7.3 \pm 2.1$ & $8.7 \pm 1.8$ & $8.8 \pm 1.5$ \\
\hline$\varnothing \mathrm{TI}$ & $4.4 \pm 1.9$ & $11.2 \pm 2.7$ & $7.6 \pm 1.8$ & $8.9 \pm 3.7$ & $8.3 \pm 4.4$ & $10.3 \pm 5.0$ \\
\hline
\end{tabular}

$B L$, Baseline; $P A P$, pulmonary artery pressure; $T I$, tricuspid insufficiency; $\emptyset T I$, without tricuspid insufficiency; $R A P$, right atrial pressure.

$\mathrm{RAP}=7.6 \pm 2.7 \mathrm{~mm} \mathrm{Hg}$ at the RV failure condition and $7.1 \pm$ $2.2 \mathrm{~mm} \mathrm{Hg}$ at $100 \% \mathrm{Q}_{\text {Shunt }}$. In the ØTI group, the effect is much larger, decreasing from $11.2 \pm 2.7 \mathrm{~mm} \mathrm{Hg}$ to $7.6 \pm$ $1.8 \mathrm{~mm} \mathrm{Hg}$ at the same conditions. However, there was no difference between the TI and $\varnothing \mathrm{TI}$ groups $(P=.67)$.

\section{Gas Exchange}

VV ECMO maintained mean oxygen saturation greater than $99 \%$ on average with an overall average $\mathrm{Po}_{2}$ of $243 \pm 102 \mathrm{~mm} \mathrm{Hg}$ (minimum, $81 \mathrm{~mm} \mathrm{Hg}$ ) and an overall average $\mathrm{PCO}_{2}$ of $38 \pm 6 \mathrm{~mm} \mathrm{Hg}$ (minimum, $18 \mathrm{~mm} \mathrm{Hg}$; maximum, $50 \mathrm{~mm} \mathrm{Hg}$ ) in the TI group (Figure 3). Similar gas exchange was evaluated in the ØTI group (Figure 4) with a mean oxygen saturation greater than $99 \%, \mathrm{Po}_{2}$ of $120 \pm 68 \mathrm{~mm} \mathrm{Hg}$ (minimum, $55 \mathrm{~mm} \mathrm{Hg}$ ), and $\mathrm{PCO}_{2}$ of $35 \pm 5 \mathrm{~mm} \mathrm{Hg}$ (minimum, $24 \mathrm{~mm} \mathrm{Hg}$; maximum, $44 \mathrm{~mm}$ $\mathrm{Hg}$ ). The $\mathrm{PO}_{2}$ and $\mathrm{PCO}_{2}$ were significantly different between the TI and ØTI groups $\left(P<.01\right.$ for both). Mean $\mathrm{RA} \mathrm{Po}_{2}$ averaged $188 \pm 84 \mathrm{~mm} \mathrm{Hg}$ across both TI groups with a mean $\mathrm{PCO}_{2}$ of $39 \pm 10 \mathrm{~mm} \mathrm{Hg}$. Similarly, mean left atrial $\mathrm{Po}_{2}$ was $211 \pm 64 \mathrm{~mm} \mathrm{Hg}$, and the mean $\mathrm{PCO}_{2}$ was $35 \pm 5 \mathrm{~mm} \mathrm{Hg}$. Disconnecting $\mathrm{O}_{2}$ supply to the oxygenator at $100 \%$ flow to the shunt resulted in a decrease in arterial $\mathrm{Po}_{2}$ to $58 \pm 4 \mathrm{~mm}$ $\mathrm{Hg}$ and an increase in arterial $\mathrm{PCO}_{2}$ to $58 \pm 16 \mathrm{~mm} \mathrm{Hg}$.

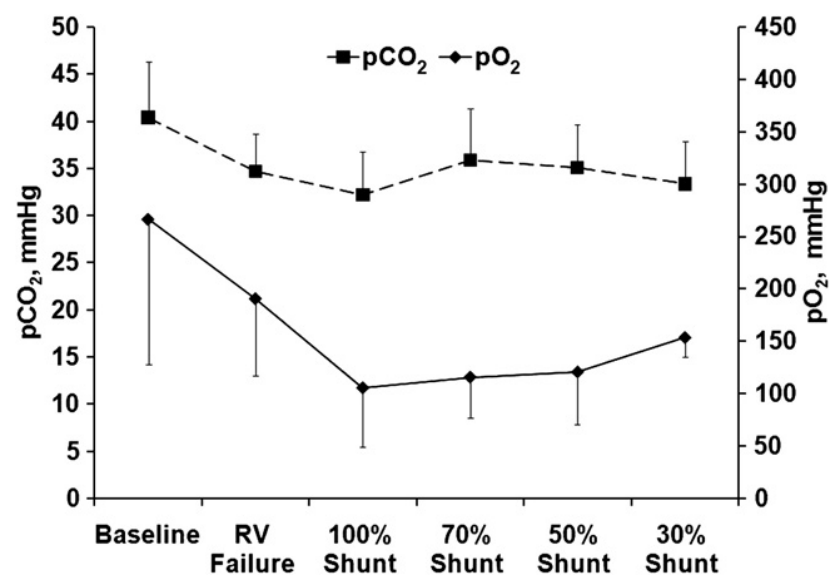

FIGURE 3. Arterial blood $\mathrm{Po}_{2}$ and $\mathrm{PCO}_{2}$ for the TI group. $R V$, Right ventricular.

\section{DISCUSSION}

The surgical exclusion of the failing right ventricle is reported to be an effective management in patients with postoperative refractory RV dysfunction. ${ }^{15}$ Therefore, volume unloading the failing right ventricle has proven successful. In the setting of severe primary pulmonary hypertension, early experimental studies in the mid-1960s and clinical observations in the mid-1980s have suggested that an interatrial shunt may be beneficial for the treatment of RV failure. ${ }^{16,17}$ The atrial septal defect allows right to left shunting and a resultant increase in systemic CO. This leads to an increase in systemic oxygen delivery despite a decrease in systemic arterial saturation. ${ }^{18-20}$ Thus, atrial septostomies are occasionally performed either as a sole treatment for refractory $\mathrm{RV}$ failure or to bridge patients to lung transplantation. ${ }^{6,7}$ However, patients with severe gas exchange deficiency are not suitable candidates for this approach. Therefore, our hypothesis was that the combination of an atrial septostomy with extracorporeal gas exchange by VV ECMO could be a successful approach to support these patients.

Various pulmonary devices have entered clinical practice to treat respiratory failure, but only a few devices and management concepts also treat ventricular failure. Of these, the

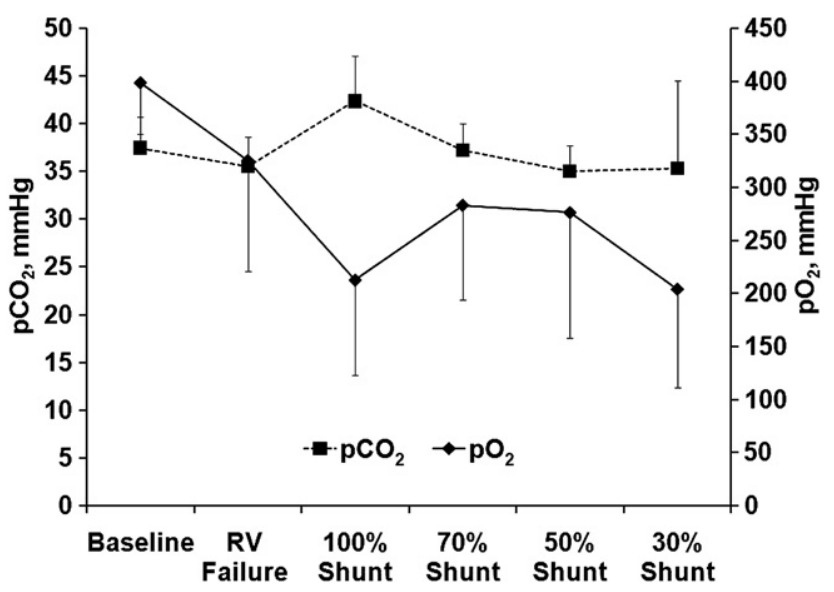

FIGURE 4. Arterial blood $\mathrm{PO}_{2}$ and $\mathrm{PCO}_{2}$ for the $\varnothing \mathrm{TI}$ group. 
paracorporeal artificial lung is a promising innovation for pulmonary and ventricular support. This artificial lung is attached between the pulmonary artery and the left atrium, thereby improving gas exchange while reducing RV afterload. ${ }^{14,21,22}$ However, this approach requires an invasive thoracotomy in critically ill patients, exposing them to the risk of anesthesia and major surgery. In addition, the artificial lung attachment results in technically more difficult lung transplantation because of induced native lung and heart adhesions.

In contrast, an atrial septostomy is performed percutaneously, oftentimes requiring only sedation rather than general anesthesia. This diminishes the risk associated with anesthesia and technically difficult major thoracic surgery. ${ }^{7}$ Furthermore, ECMO does not necessarily require sedation, and it is perfectly feasible in an alert, extubated, spontaneously breathing patient, the ideal transplant candidate. ${ }^{23}$ Novel technical achievements, such as the 2009 Food and Drug Administration-approved double-lumen cannula for veno-venous gas exchange, facilitate the use of ECMO as a percutaneously introduced portable paracorporeal lung. ${ }^{24}$ This new cannula for adult ECMO support is introduced into the jugular vein draining from both vena cavae and reinfusing into the right atrium directly through the tricuspid valve into the right ventricle. It may be that this novel cannula will improve flows of oxygenated blood to the left atrium in the setting of a combined ECMO and atrial septal defect support. On the other hand, ECMO causes larger activation of blood components than paracorporeal artificial lungs because of its large circuit and mechanical pump. Thus, the resulting systemic inflammatory response and thrombogenicity are greater.

The study presented was designed to examine the effectiveness of right to left atrial shunting with VV ECMO at treating high-afterload RV failure. Our results indicate that right to left atrial shunting is capable of treating acute severe RV failure, here defined by a $40 \%$ to $60 \%$ decrease in CO. This degree of RV failure would otherwise be fatal. The necessary amount of right to left atrial shunt flow needed to treat this degree of acute RV failure seems to be as low as approximately $8 \%$ of baseline $\mathrm{CO}$ to avoid $\mathrm{RV}$ failure when TI is present but ideally greater than $20 \%$ to maintain baseline CO. However, the animals of this study did not have the typical hypertrophic ventricle present in patients with chronic lung disease. The required shunt fraction in a hypertrophied RV may be lower because the RV is already adapted to high afterloads.

All animals with TI survived the entire experiment, but sheep without TI required a $Q_{\text {Shunt }}$ greater than $13 \%$ of baseline $\mathrm{CO}$ to avoid complete RV failure and death. The insufficient tricuspid valve likely acts as a "pop off valve," allowing a slightly greater blood flow through the atrial septal defect (Figure E2) in the TI group. This result is not fully explained by the hemodynamic data from this study, be- cause statistical comparison did not find significant differences between the TI and ØTI groups for all measured parameters. The cause of this is that ØTI animals with poorer hemodynamics died earlier in the course of the experiment, leaving only animals with better RV function. Thus, small differences in shunt flow between the groups at $100 \% \mathrm{Q}_{\text {shunt }}$ disappeared at lower shunt flows as weaker members of the ØTI group died. Finally, because stable hemodynamics were maintained regardless of the presence of TI, a combined VV ECMO and interatrial shunt support might be applicable for both group of patients.

The shunt was able to unload the right ventricle sufficiently to allow increased CO but not sufficiently to reduce RVP. As the shunt resistance decreased, the overall resistance of the right ventricle to left atrial flow pathway was reduced. This led to greater volume unloading of the RV and a small, statistically insignificant decrease in RAP. There were no RV volume measurements in this study, but it is likely that RV enddiastolic volume was also reduced. Such a reduction leads to a reduction in the ventricular work necessary to pressurize blood before ejection, and this work was likely used instead to generate more productive stroke work. Thus, $\mathrm{CO}$ increased with increasing shunt flow, and as a result, mean RVP remained elevated despite the volume unloading. Because $\mathrm{CO}$ was returned to a normal value at $100 \% \mathrm{Q}_{\text {Shunt }}$, further increases in shunt flow would likely have no effect on $\mathrm{CO}$ and thus result in lower RVP. This may be possible with a less resistant atrial septal defect created via septostomy.

These results are comparable to a similar study conducted by Zierer and collagues. ${ }^{25}$ In that study, low versus high atrial shunt flow was compared in dogs with chronic right heart failure after 3 to 4 months of progressive pulmonary artery banding. The role of the tricuspid valve in atrial shunting was not considered. The authors reported that $\mathrm{CO}$ increased beyond baseline with a shunt flow equal to $15 \%$ of CO. On the other hand, a shunt flow of $29 \%$ of $\mathrm{CO}$ did not increase $\mathrm{CO}$ beyond baseline. The authors concluded that high flows seem to exceed an ideal shunt fraction. In comparison, our results indicate that a shunt fraction between $20 \%$ and $30 \%$ of baseline $\mathrm{CO}$ is capable of treating $\mathrm{RV}$ failure, and a shunt fraction less than $20 \%$ of baseline $\mathrm{CO}$ results in decreased $\mathrm{CO}$. The reason for this discrepancy is explained by a different study design. The animals of the present study had normal hearts without RV hypertrophy and a more severe, acute RV failure, perhaps diminishing the $\mathrm{CO}$ increase at small shunt flows, but also provided gas exchange, allowing better function at high shunt flows.

\section{Study Limitations}

The present study was designed to examine a bridge to transplantation for patients with chronic pulmonary hypertension caused predominantly from pathologies in the peripheral vascular tree and consecutive RV failure. However, our study more closely resembles acute RV failure 
similar to a severe pulmonary embolism. Despite this, the proposed bridge is designed for critically ill patients who have had an acute-on-chronic event (eg, acute pneumonia) leading to a severe deterioration of pulmonary hypertension and RV failure. The presented animal model simulates this clinical scenario for the most part. Nonetheless, improved results may be achieved using animals with chronic pulmonary hypertension and a partially compensated right ventricle.

\section{CONCLUSIONS}

Right to left atrial shunting of oxygenated blood with VV ECMO is capable of eliminating acute, severe, normally lethal RV failure while maintaining normal arterial blood gases. The presence of TI seems to improve RV function during application of this potentially novel technique to bridge patients to lung transplantation.

\section{References}

1. Humbert M, Sitbon O, Chaouat A, et al. Pulmonary arterial hypertension in France: results from a national registry. Am J Respir Crit Care Med. 2006;173: 1023-30.

2. Thenappan T, Shah SJ, Rich S, Gomberg-Maitland M. A USA-based registry for pulmonary arterial hypertension: 1982-2006. Eur Respir J. 2007;30:1103-10.

3. Stupi AM, Steen VD, Owens GR, et al. Pulmonary hypertension in the CREST syndrome variant of systemic sclerosis. Arthritis Rheum. 1986;29:515-24.

4. US Department of Health and Human Services. Organ Procurement and Transplant Network Web site. Report OSA. Available at: www.optn.org. Accessed May 10, 2010

5. McLaughlin VV, Presberg KW, Doyle RL, et al. Prognosis of pulmonary arterial hypertension: ACCP evidence-based clinical practice guidelines. Chest. 2004; 126:78S-92.

6. Rothman A, Sklansky MS, Lucas VW, et al. Atrial septostomy as a bridge to lung transplantation in patients with severe pulmonary hypertension. Am J Cardiol. 1999;84:682-6.

7. Kurzyna M, Dabrowski M, Bielecki D, et al. Atrial septostomy in treatment of end-stage right heart failure in patients with pulmonary hypertension. Chest. 2007;131:977-83.

8. Broome M, Palmer K, Schersten H, Frenckner B, Nilsson F. Prolonged extracorporeal membrane oxygenation and circulatory support as bridge to lung transplant. Ann Thorac Surg. 2008;86:1357-60.

9. Jackson A, Cropper J, Pye R, et al. Use of extracorporeal membrane oxygenation as a bridge to primary lung transplant: 3 consecutive, successful cases and a review of the literature. J Heart Lung Transplant. 2008;27:348-52.
10. Bartlett RH, Roloff DW, Custer JR, Younger JG, Hirschl RB. Extracorporeal life support: the University of Michigan experience. JAMA. 2000;283: 904-8.

11. Peek GJ, Moore HM, Moore N, Sosnowski AW, Firmin RK. Extracorporeal membrane oxygenation for adult respiratory failure. Chest. 1997;112: 759-64.

12. Fischer S, Bohn D, Rycus P, et al. Extracorporeal membrane oxygenation for primary graft dysfunction after lung transplantation: analysis of the Extracorporeal Life Support Organization (ELSO) registry. J Heart Lung Transplant. 2007; 26:472-7.

13. Peek GJ, Mugford M, Tiruvoipati R, et al. Efficacy and economic assessment of conventional ventilatory support versus extracorporeal membrane oxygenation for severe adult respiratory failure (CESAR): a multicentre randomised controlled trial. Lancet. 2009;374:1351-63.

14. Sato H, Hall CM, Lafayette NG, et al. Thirty-day in-parallel artificial lung testing in sheep. Ann Thorac Surg. 2007;84:1136-43.

15. Kunihara T, Dzindzibadze V, Aicher D, Schafers HJ. Bidirectional cavopulmonary shunt for acute right ventricular failure in an adult patient. Ann Thorac Surg. 2004;78:1066-8.

16. Austen WG, Morrow AG, Berry WB. Experimental studies of the surgical treatment of primary pulmonary hypertension. J Thorac Cardiovasc Surg. 1964;48: 448-55.

17. Hopkins WE, Ochoa LL, Richardson GW, Trulock EP. Comparison of the hemodynamics and survival of adults with severe primary pulmonary hypertension or Eisenmenger syndrome. J Heart Lung Transplant. 1996;15:100-5.

18. Sandoval J, Rothman A, Pulido T. Atrial septostomy for pulmonary hypertension. Clin Chest Med. 2001;22:547-60.

19. Sandoval J, Gaspar J, Pulido T, et al. Graded balloon dilation atrial septostomy in severe primary pulmonary hypertension. A therapeutic alternative for patients nonresponsive to vasodilator treatment. J Am Coll Cardiol. 1998;32: 297-304.

20. Klepetko W, Mayer E, Sandoval J, et al. Interventional and surgical modalities of treatment for pulmonary arterial hypertension. J Am Coll Cardiol. 2004;43: $73 \mathrm{~S}-80$.

21. Schmid C, Philipp A, Hilker M, et al. Bridge to lung transplantation through a pulmonary artery to left atrial oxygenator circuit. Ann Thorac Surg. 2008; $85: 1202-5$.

22. Strueber M, Hoeper MM, Fischer S, et al. Bridge to thoracic organ transplantation in patients with pulmonary arterial hypertension using a pumpless lung assist device. Am J Transplant. 2009;9:853-7.

23. Garcia JP, Iacono A, Kon ZN, Griffith BP. Ambulatory extracorporeal membrane oxygenation: a new approach for bridge-to-lung transplantation. J Thorac Cardiovasc Surg. 2010;139:e137-9. Epub 2010 Mar 9.

24. Wang D, Zhou X, Liu X, et al. Wang-Zwische double lumen cannula-toward a percutaneous and ambulatory paracorporeal artificial lung. ASAIO J. 2008; 54:606-11.

25. Zierer A, Melby SJ, Voeller RK, Moon MR. Interatrial shunt for chronic pulmonary hypertension: differential impact of low-flow vs. high-flow shunting. Am J Physiol Heart Circ Physiol. 2009;296:H639-44. 


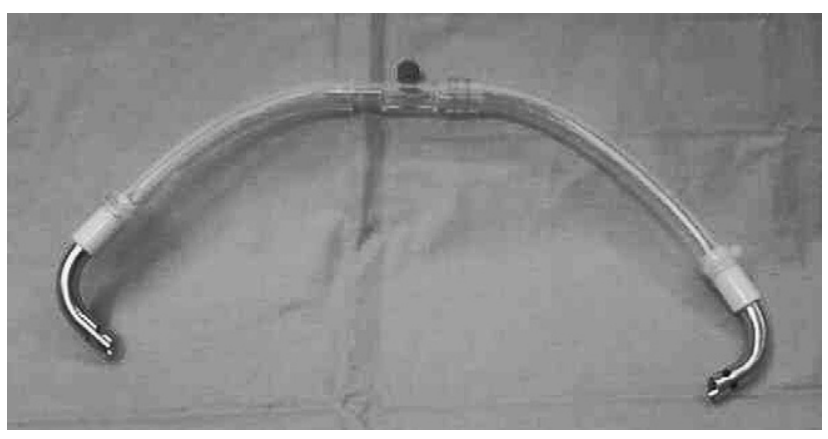

FIGURE E1. Right to left atrial shunting was simulated with a custommade $31 \mathrm{~F}$ extracardiac shunt introduced into the atrial appendages.

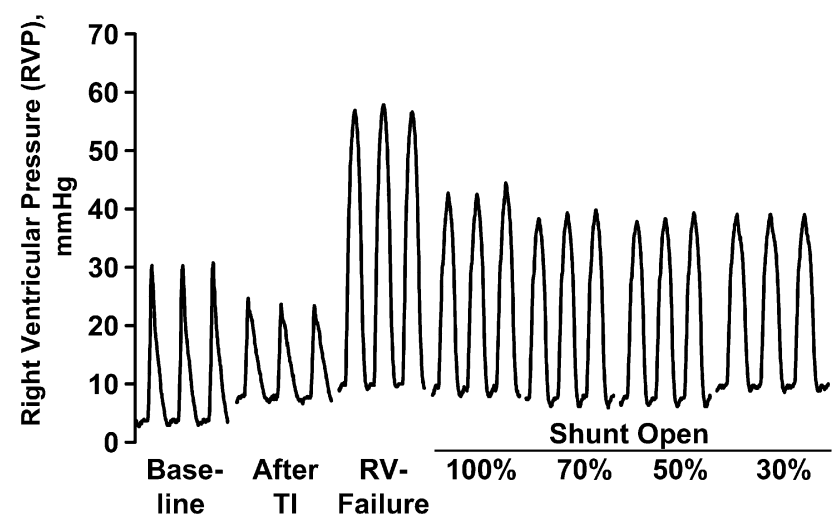

FIGURE E3. Typical examples of RVP tracings at each condition. $R V$, Right ventricular.

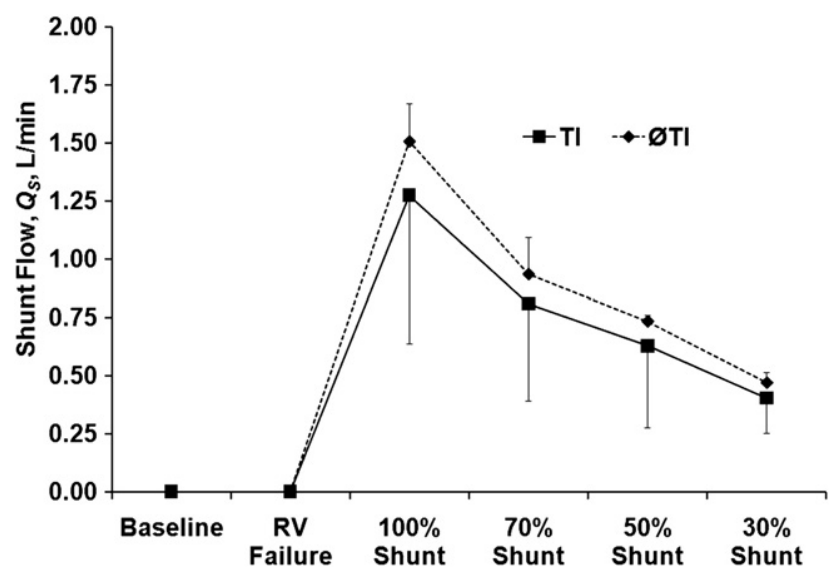

FIGURE E2. Q ${ }_{\text {Shunt }}$ at each shunt condition in TI and ØTI groups. $R V$, Right ventricular; $T I$, tricuspid insufficiency; $\varnothing T I$, without tricuspid insufficiency; $Q_{\text {Shunt }}$, shunt flow rate. 